\title{
Use of cyanoacrylate for the stabilization of tissues in root coverage procedures: A case series report with 5 years follow up.
}

\author{
Javier Patricio Rojas-Cortez ${ }^{1 *}$, Leonardo Augusto Rachele-Righesso ${ }^{2}$, Leticia Andrea Rojas-Cortez ${ }^{3}$
}

\author{
1. Private practice. Clínica Dr. Nicolas Troncoso. La \\ Dehesa, Santiago, Chile. \\ 2. PhD Candidate. Clinic for Oral and Maxillofacial \\ Surgery and Plastic Surgery, University Medical \\ Center of the Johannes Gutenberg University. \\ Mainz, Germany. \\ 3. PhD Candidate. Translational Allergy and \\ Immunology Laboratory, Faculty of Medicine, \\ Pontificia Universidad Católica de Chile, Santiago, \\ Chile.
}

* Corresponding author: Javier Patricio Rojas

Cortez | Address: Marchant Pereira 2950,

Depto.306. Ñuñoa. Santiago. Chile | Phone: +56 9

33406705 | E-mail: dr.javierrojasc@gmail.com

Work received on 21/05/2020.

Revised work: 22/06/2020

Approved for publication on 11/07/2020

\begin{abstract}
A variety of periodontal plastic surgery techniques have been proposed to correct aesthetic and functional problems caused by gingival recession, with root coverage using connective tissue grafts being the one most commonly performed. These surgeries, however, are partially dependent on tissue graft stability. In this case series, we describe the use of a tissue adhesive (cyanoacrylate) as a solution for graft stabilization. Two patients with Cairo's type 1 gingival recession were treated with an envelope technique using connective tissue graft stabilized with cyanoacrylate alone. The results were a faster procedure and complete root coverage, even after 5 years of follow-up. Our findings suggest that cyanoacrylates can be an alternative to standard graft stabilizing procedures, leading to a stable root coverage in RT1 recessions. KEY WORDS:
\end{abstract}

Cyanoacrylates; Gingival recession; Tissue adhesives.

Int. J. Inter. Dent Vol. 14(2); 191-193, 2021.

\section{INTRODUCTION}

Periodontal plastic surgery is defined as a surgical procedure to prevent, correct, or eliminate developmental/traumatic deformities of the gingiva and alveolar mucosa. Among its objectives are to recover the morphology, position and dimension of the periodontal tissues that surround the tooth or the dental implant ${ }^{(1)}$.

One of the most common indications for periodontal plastic surgery is the treatment of gingival recession ${ }^{(1)}$. Gingival recession has been defined as the displacement of the marginal gingiva towards the apical zone of the amelocemental junction, leading to exposure of the root surface ${ }^{(2)}$. Its etiology comprises a series of factors, such as poor attached gingiva, poor dental position, crowding, root prominence, bone dehiscence, high insertion of braces that facilitate traction to the apical margin of the gingiva during movements, inflammation, traumatic toothbrushing, gingival laceration, inadequate design of removable prosthesis, and uncontrolled orthodontic tooth movements ${ }^{(1)}$.

The indications for root coverage surgery include the presence of aesthetic problems, hypersensitivity, susceptibility to root caries, lack of attached gingiva and cervical abrasion ${ }^{(3)}$.

Multiple surgical modalities have been proposed to aesthetic esthetic and functional root coverage. Of these, the subepithelial connective tissue graft stands out, for it has been shown to be highly successful and predictable, due to its dual source of nutrition ${ }^{(2,4)}$. One of the techniques used in combination with the subepithelial connective graft is the envelope technique, showing recession coverage results close to $80 \%$, of which $42 \%$ obtain complete coverage $^{(5)}$. In particular, it has been shown that in Miller's class I and II recessions treated with the envelope technique and subepithelial connective tissue grafts, a coverage of $88.7 \%$ and an increase in keratinized gingiva of 2,14 $\mathrm{mm}$. has been achieved 12 months after surgery ${ }^{(6)}$.

Some studies indicate that root coverage surgeries using connective tissue grafts can be time-consuming, have a high learning curve, and present a high number of trans- and postoperative complications, especially when performed by inexperienced clinicians ${ }^{(7)}$.

Regarding synthesis, sutures have long been shown to provide adequate wound closure with a minimal rate of dehiscence. However, their use in root coverage has some disadvantages. The biggest disadvantage being an increase in the surgical time, it also traumatizes tissues, affecting vascularization and increasing the risk of tearing of the flap ${ }^{(8)}$. Additionally, depending on the material, it can pinch and cause discomfort to patients or favor the accumulation of plaque, increasing susceptibility to infection ${ }^{(9)}$.

An alternative to sutures are tissue adhesives, which are biocompatible agents that, when applied to skin or mucosa, establish a resistance to wound dehiscence through attractive forces between the tissue and adhesive molecules. Among the desirable characteristics of tissue adhesives is the capacity to hold tissues in place for as long as necessary for natural healing to occur. They should be manually removed once healing has taken place, lest a foreign body reaction is triggered, hindering wound healing ${ }^{(10)}$.

Cyanoacrylates correspond to a group of low-cost cyanoacrylic acid esters used in general and pediatric surgery. This adhesive has biocompatible, biodegradable, hemostatic properties, and a long half-life, making it an ideal adhesive agent for the oral environment ${ }^{(10)}$.

Cyanoacrylates interact with tissues in a stable way over time (about 7 to 10 days). In addition, they polymerize in contact with skin and especially with mucosa, since this process is accelerated by moisture, forming very strong bonds. This polymerization binds tissues, acting as a sealant and preventing bleeding and the accumulation of food or bacteria in the wound ${ }^{(8)}$. These adhesives can be found in liquid or strip form, the former being most frequently used in the medical and dental practice ${ }^{(10)}$.

The main disadvantage of cyanoacrylates is their low capacity to correct the position of the tissue once the adhesive has been applied. Thus, extreme care is required when placing the tissues prior to sealing ${ }^{(10)}$.

To the best of the authors knowledge there are no studies on the use of dental cyanoacrylate to stabilize the flap and connective tissue in root coverage surgeries. Hence, we present an unprecedented case series on the use of cyanoacrylate as an alternative to sutures for this purpose.

\section{CASE REPORT}

\section{Case 1}

A 43-year-old male, ASA I, patient sought treatment for gingival retraction and hypersensitivity in tooth 24 . At clinical examination, a gingival recession type (RT) 1 (according to Cairo's classification system $\left.{ }^{(8)}\right), 2 \mathrm{~mm}$. in length, was diagnosed (Fig. 1). Probing depth (PD) and clinical attachment level (CAL) were $1 \mathrm{~mm}$. and $4 \mathrm{~mm}$., respectively (Table 1 ). The characteristics of the gingival margin, gingival thickness and dental morphology were compatible with a thick biotype. Scaling and hygiene instructions were performed one week before surgery. The patient was informed of the risks and benefits and signed an informed consent.

The root coverage procedure was performed using an envelope technique ${ }^{(5)}$, aiming to fully cover the exposed root area, reestablishing the natural gingival contour and treating the hypersensitivity.

The procedure was performed under local anesthesia. Both donor and recipient sites were anesthetized using $2 \%$ lidocaine with epinephrine 1 : 100.000 (Lignospan, Septodont. France). The root scaling of the exposed surface was performed with a Gracey curette No. 5/6 (American Eagle, Missoula, USA). A partial thickness incision was done in to the sulcus of the 


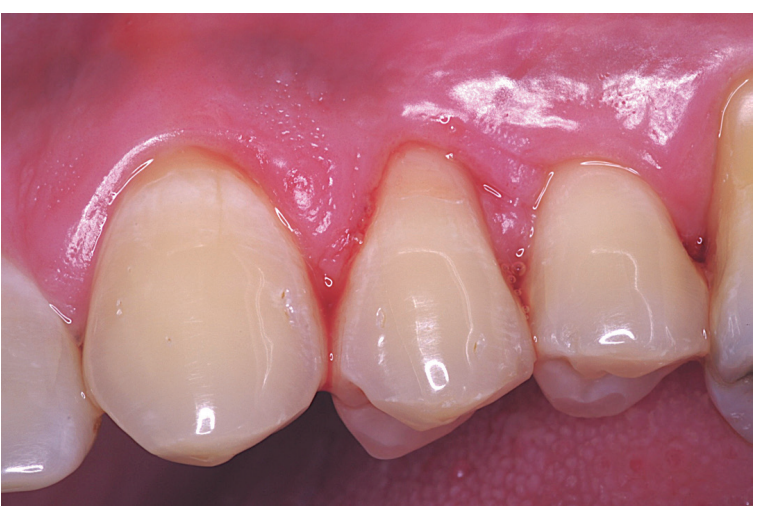

Figure 1. Baseline recession in tooth 2.4: The recession class RT1 of Cairo is $2 \mathrm{~mm}$. length. The phenotype was classified as thick.

tooth 2.4 with a microsurgical blade No. 69 (Swann-Morton Ltd., Sheffield, England). The preparation of the envelope (recipient site) was carried out using instruments specific for this purpose (TKN 1) (Medesy, Maniago, Italy).

A connective tissue graft was harvested from the palate making a $1.5 \mathrm{~cm}$ incision with a 15c scalpel blade (Swann-Morton Ltd. Sheffield, England). Next, the graft was de-epithelized. Adipose tissue remnants were removed using Le Grange scissors (Medesy, Maniago, Italy). The wound area in the palate was then covered with a dental cyanoacrylate (PeriAcryl ${ }^{\circledR} 90 \mathrm{HV}$, GluStitch Inc., Vancouver, Canada).

The connective tissue graft was inserted in the recipient bed, leaving $2 \mathrm{~mm}$. exposed (final position); the surgical wound was washed with saline solution and dried with gauze. Finally, 2 layers of tissue adhesive (PeriAcryl ${ }^{\circledR 90} \mathrm{HV}$, GluStitch Inc., Vancouver, Canada) were applied on the surface of the tissues using a rubbing technique, until a compact and stable structure was achieved (3 layers of adhesive) (Fig. 2). The whole procedure took 20 minutes.

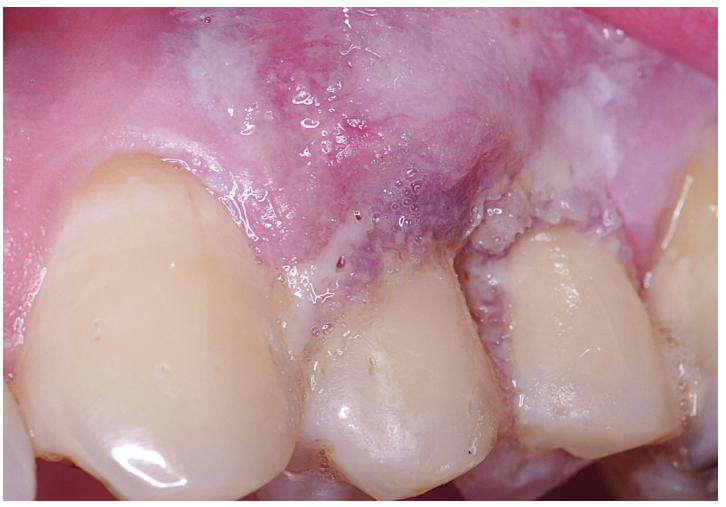

Figure 2. Envelope technique with an exposed connective tissue graft: The graft was inserted and leaved expose $2 \mathrm{~mm}$. The tissue adhesive was covering the flap and the graft stabilizing the area for 10 days.

For post-operative care, the patient was instructed to keep a soft diet for 7 days, drink plenty of liquids, and not brush the operated areas for 4 weeks. Follow-up consultations took place at 7, 14, 60, 180 days, and 5 years postsurgery. At 14 days, the tissue adhesive was loose and the dentist removed it. If the product accidentally be swallowed, no side-effects are expected, according to the manufacturer. At 60 days, complete coverage of the recession was achieved. At 5 years, the gingival margins were stable, as clinically assessed (Fig. 3). The PD and CAL were both of $1 \mathrm{~mm}$. (Table 1)

Table 1. Probing depth (PD) and clinical attachment (CAL) level before treatment and after 5 years.

\begin{tabular}{|c|c|c|c|c|c|}
\cline { 3 - 6 } \multicolumn{2}{c|}{} & \multicolumn{2}{c|}{ BASAL } & \multicolumn{2}{c|}{ 5 YEARS } \\
\cline { 3 - 6 } \multicolumn{2}{c|}{} & $\begin{array}{c}\text { PD } \\
(\mathbf{m m} .)\end{array}$ & $\begin{array}{c}\text { CAL } \\
(\mathbf{m m} .)\end{array}$ & $\begin{array}{c}\text { PD } \\
(\mathbf{m m} .)\end{array}$ & $\begin{array}{c}\text { CAL } \\
(\mathbf{m m} .)\end{array}$ \\
\hline CASE 1 & 2.4 & 1 & 4 & 1 & 1 \\
\hline \multirow{2}{*}{ CASE 2 } & 1.2 & 1 & 2 & 1 & 1 \\
\cline { 2 - 6 } & 1.3 & 1 & 3 & 1 & 1 \\
\hline
\end{tabular}

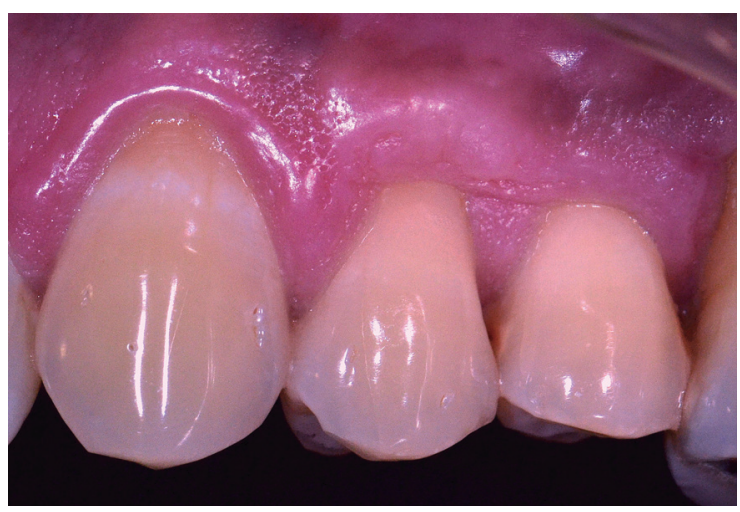

Figure 3. Result 5 years after the surgery: The margins are stable with $\mathrm{PD}$ of $1 \mathrm{~mm}$. and CAL of $1 \mathrm{~mm}$.

\section{Case 2}

A 51-year-old female, ASA I, patient sought treatment for receding gums in teeth 1.3 and 1.2. At clinical examination, two recessions RT1 were diagnosed: one in tooth 1.3 with $2 \mathrm{~mm}$. in length, and another one in tooth 1.2 with $1 \mathrm{~mm}$. (Fig. 4). In tooth 1.3 , the PD and CAL were $1 \mathrm{~mm}$. and 3 $\mathrm{mm}$., respectively, while in tooth $1.2 \mathrm{PD}$ and CAL were $1 \mathrm{~mm}$. and $2 \mathrm{~mm}$. (Table 1). The characteristics of the gingival margin, thickness of the gingiva and dental morphology and transparency of the probe were compatible with a thin biotype. The surgical protocol and postoperative recommendations described above for patient 1 were followed for this patient as well (Fig.5). The aim of the surgery was to increase the gingival thickness, thus developing a thick phenotype, in order to achieve complete coverage of the recession. The patient was informed of the risks and benefits and signed an informed consent.

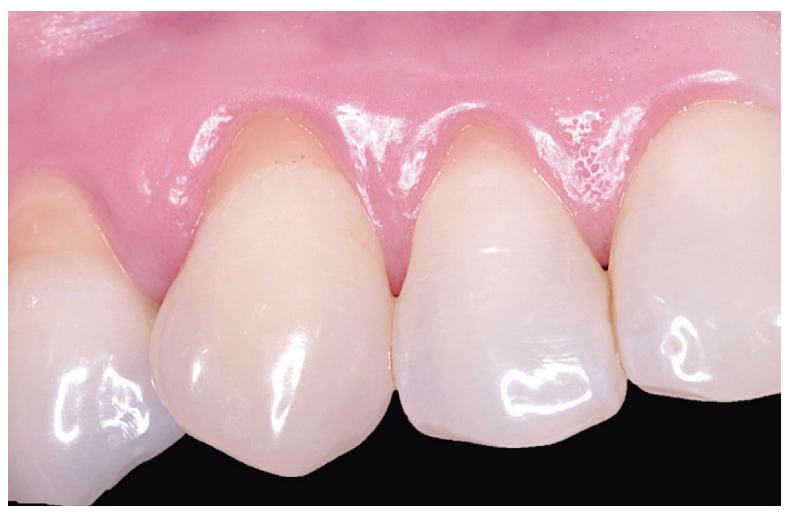

Figure 4. Baseline recessions: The recessions class RT1 of Cairo in 1.3 and 1.2 are $2 \mathrm{~mm}$. and $1 \mathrm{~mm}$. length, respectively. The phenotype was classified as thin.

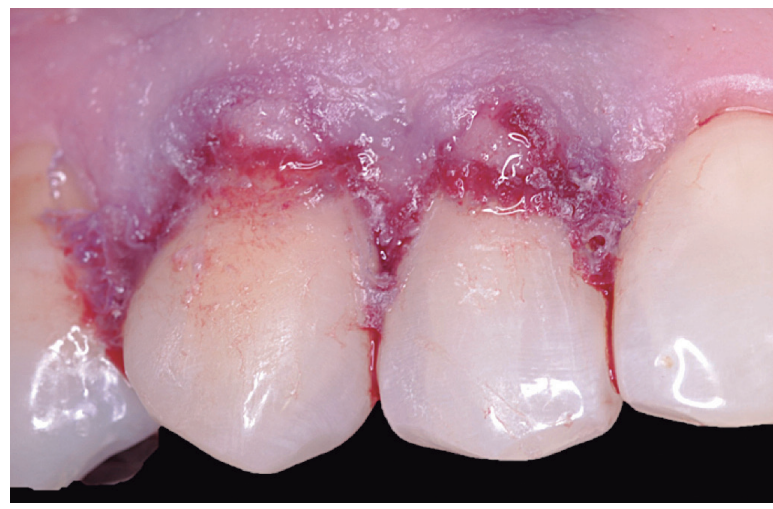

Figure 5. Tunnel technique with an exposed connective tissue graft: The graft was inserted in 1.3/1.2 and leaved expose $2 \mathrm{~mm}$. and $1 \mathrm{~mm}$.. The tissue adhesive is covering the flap and the graft stabilizing the area for 14 days.

This time, the procedure took 23 minutes. At 14 days, the tissue adhesive detached on its own. At 60 days, complete coverage of the recession was 
achieved. At 5 years, the gingival margins were stable. In tooth 1.3 , the PD and CAL were $1 \mathrm{~mm}$. and $1 \mathrm{~mm}$., respectively, while in tooth $1.2 \mathrm{PD}$ and CAL were both $1 \mathrm{~mm}$. (Table 1), values that remained stable over 5 years (Fig.6).

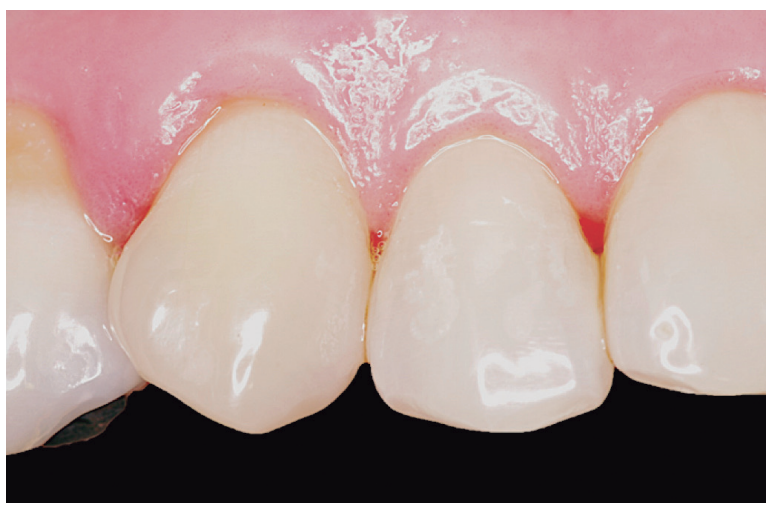

Figure 6. Result 5 years after the surgery: The margins are stable with PD of $1 \mathrm{~mm}$. and CAL of $1 \mathrm{~mm}$.

\section{DISCUSSION}

Covering exposed root surfaces has become an integral part of periodontal surgical practice, due to an increased demand for these treatments ${ }^{(11,12)}$. The treatment of gingival recessions can be carried out following different surgical techniques and the available scientific evidence shows that connective tissue grafting presents the best results in terms of amount of attached gingiva formed and percentage of root coverage ${ }^{(13)}$.

Subepithelial connective tissue grafts are the standard when facing a gingival recession, especially if greater root coverage is needed, as it provides a good aesthetic result. It also significantly reduces the chance of graft avascular necrosis, since the receiving area receives a double vascular supply ${ }^{(13,14)}$.

Wound closure is critical for a successful surgery. Suboptimal suturing or postoperative care by the patient may lead to complications, like graft loss ${ }^{(6)}$.

In this report, the envelope technique ${ }^{(5)}$ was used as a basis for the surgical procedure; a coronal advancement flap was not performed, but 1 to $2 \mathrm{~mm}$. of connective tissue was left exposed. A systematic review with an 18-month follow-up compared connective grafts completely covered through coronal advancement flap versus partial exposure, and concluded that there was no difference in probing depth, clinical attachment level, or in the healing processes between these two techniques ${ }^{(11)}$. Additionally, a systematic review indicates that it is possible to expose connective tissue up to $2.8 \pm 1.1 \mathrm{~mm}$. ${ }^{(11)}$. Exposed connective tissue has shown a significant increase in attached gingiva, tissue thickness, and a decrease in recurrence of the gingival recession ${ }^{(11)}$. Accordingly, in this case series both patient treatments presented stable results 5 years after surgery.

Regarding procedure duration, we observed a mean of 21 minutes. A study by Zuchelli et al. indicates an average chair time in root coverage surgeries of about 40 minutes $^{(15)}$. Given the authors are highly skilled periodontist, we speculate that a time-consuming suturing process might be why it took them considerably longer. When cyanoacrylates are used, the application time is around 30 seconds.

Reports indicate that this type of surgical technique has a high learning curve, as evidenced by a high percentage of graft loss by inexperienced clinicians. They are also time-consuming and prone to complications, such as pain, bleeding and suture dehiscence, which often leads to surgica failure ${ }^{(7,13)}$. Some of these issues could be solved using tissue adhesives.

Tissue adhesives also create a strong adherence surface, stabilizing the graft without perforating the flap and thus ensuring a better blood supply. Moreover, they work as a protective layer, preventing food from entering the wound or the connective tissue graft from detaching, making surgical procedures more predictable ${ }^{(10)}$.

\section{CONCLUSION}

In the presented cases, adequate stabilization of the flap and connective tissue graft was achieved using dental cyanoacrylate, reducing surgical time and showing stable results after 5 years of follow-up. In an unprecedented manner we provide preliminary evidence of the efficacy of cyanoacrylatebased tissue adhesive for root coverage. As a next step, cohort studies with a larger sample size and a control group should follow.

\section{CLINICAL JUSTIFICATION FOR THE STUDY}

Novel tissue bonding compounds like cyanoacrylates are currently available in the medical market for skin injuries with great efficacy. However, the little evidence of this agents in oral procedures have slow down their usage in the periodontal clinical practice.

\section{MAIN RESULTS}

In particular, this paper highlights a novel biocompatible bonding agent with promising results to stabilized the tissues in root coverage procedures as an alternative to conventional suture with a stable clinical result after 5 years follow up.

\section{PRACTICAL CONSEQUENCES}

The use of cyanoacrylates to stabilized tissues in combination with minimally invasive surgical techniques seems to be a reliable alternative to sutures showing a stable clinical result after 5 years follow up.

\section{CONFLICT OF INTEREST AND FUNDING SOURCE}

Javier Rojas is involved in the company GluStitch Inc. and has received financial support for congresses and workshops. The project was funded by the author. The cyanoacrylate used in this study was donated by the company GluStitch, Vancouver, Canada. The other authors have no conflicts of interest.

\section{References}

1. Miller PD. A classification of marginal tissue recession. Inter $\mathrm{J}$ Periodontol Restorative Dent. 1985;5(2):9-13.

2. Aroca S, Molnár B, Windisch P, Gera I, Salvi GE, Nikolidakis D, et al. Treatment of multiple adjacent Miller Class I and II gingival recessions with a Modified Coronally Advanced Tunnel (MCAT) technique and a collagen matrix or palatal connective tissue graft: a randomized, controlled clinical trial. J Clin Periodontol. 2013;40(7):713-20.

3. Miller PD Jr. Regenerative and Reconstructive periodontal plastic surgery. Mucogingival surgery. Dent Clin North Am. 1998;32(2):287-306.

4. Haeri A, Serio F. Mucogingival surgical procedures: A review of the literature. Quintessence Int. 1999;30(7):475-83.

5 . Raetzke PB. Covering localized areas of root exposure employing the envelope technique. J Periodontol. 1985;56(7):397-402.

6. Tal M, Moses O, Zohar R, Meir H, Nemcovsky C. Root coverage of advance gingival recession: A comparative study between acelular dermal matrix Allograft and subepithelial connective tissue grafts. J Periodontol. 2002;73(12):1405-11.

7. Zucchelli G, Mounssif I. Periodontal plastic surgery. Periodontol 2000. 2015; 68(1):333-68.

8. Cairo F, Pagliaro U, Nieri M. Treatment of gingival recession with coronally advanced flap procedures: a systematic review. J Clin Periodontol. 2008;35:(8 Suppl)136-62.
9. Javed F, Al-Askar M, Almas K, Romanos G, Al-Hezaimi K. Tissue reactions to various suture materials used in oral surgical interventions. ISRN Dent. 2012;2012:1 6.

10. Gümüş P, Buduneli E. Graft stabilization with cyanoacrylate decreases shrinkage of free gingival grafts. Aust Dent J. 2014; 59(1)57-64.

11. Dodge A, Garcia J, Luepke P, Lai YL, Kassab M, Lin GH. The effect of partially exposed connective tissue graft on root coverage outcomes: a systematic review and meta-analysis. Eur J Oral Sci. 2018; 126:(2):84-92.

12. Vicario-Juan $M$, Pascual-LaRocca A, Vives-Bonet MT, Santos-Alemany A. Técnicas de cirugía mucogingival para el recubrimiento radicular. RCOE 2006;11(1):61-73.

13. Rocuzzo M, Bunino M, Needleman I, Sanz M. Periodontal plastic surgery for treatment of localized gingival recessions: a systematic review. J Clin Periodontol. 2002;29:(Suppl. 3):178-94

14. Bertoldi C, Bencivenni D, Lucchi A, Consolo U. Augmentation of keratinized gingiva through bilaminar connective tissue grafts: a comparison between two techniques. Minerva Stomatol. 2007; 56:(1-2):3-20.

15. Zuchelli G, Mele M, Mazzotti C, Marzadori M, Montebugnoli L, De Sanctis M. Coronally advanced flap with and without vertical incisions for the treatment of multiple gingival recessions: A comparative controlled randomized clinical trial. $J$ Periodontol. 2009; 80:(7):1083-94. 